\title{
Relationship between Pulse Wave Velocity and Carotid Atherosclerosis in Geriatric People
}

\author{
$\begin{array}{lllll}\text { L. Shen } & \text { W. Wu } & \text { B. You } & \text { H. Gao } & \text { C. Wang } \\ & \text { Y. Liu } & \end{array}$ \\ aDepartment of Geriatrics, and ${ }^{\mathrm{b}}$ Department of Cerebral Vascular Disease of Qilu Hospital, Shandong University, Jinan, China
}

\section{Key Words}

Cerebral angiography - Carotid atherosclerosis • Pulse wave velocity • Carotid intima media thickness

\begin{abstract}
Objective: To investigate the relationship between the pulse wave velocity (PWV) and angiographic carotid atherosclerosis in elderly patients. Method: 103 consecutive elderly patients were divided into two groups according to the results of cerebral angiography: carotid atherosclerosis group and normal carotid angiogram group. Basic clinical information was required by a standardized questionnaire. Carotid-femoral PWV (cfPWV) as a marker of Stiffness of artery was measured, Carotid intima media thickness (IMT) and carotid stenosis degree in angiography was evaluated. Independent-sample $t$ test was used to evaluate the difference in cfPWV between the two groups, Bivariate associations between CfPWV and an index of extracoronary atherosclerosis (IMT and severity of stenosis) was performed. Result: Among 103 subjects, 55 with carotid atherosclerosis and 48 with a normal carotid angiogram, a significant difference between the two groups in IMT and PWV was found $(P<0.05)$, and the cfPWV was significantly correlated with IMT $(r=0.3222, P=0.0315)$, but not severity of carotid stenosis $(r=0.1573, P=0.3137)$. Conclusion: cfPWV showed a positive correlation to carotid IMT, and maybe is a potentially useful adjunctive atherosclerotic risk marker to Identify of early carotid atherosclerosis.
\end{abstract}

Copyright $\odot 2011$ S. Karger AG, Basel
Vascular disease resulting from arteriosclerosis is a serious worldwide health risk [1]. It is reported that approximately $30 \%$ of ischaemic strokes are caused by the carotid artherosclerosis [2]. Early diagnosis and intervention in vascular disease is important to control adverse cerebral and cardiovascular events, such as stroke, transient ischaemic attack (TIA), acute myocardial infarction, and cardiac death [3]. Stiffness is an important characteristic of the arteries and a direct reflection of the condition of these blood vessels, and reduced arterial elasticity is a sensitive marker that indicates damage to the blood vessel wall [4]. Most of the landmark studies in this area have used carotid-femoral pulse wave velocity (cfPWV) to quantify central arterial stiffness [5-7], and $\mathrm{PWV}$ of the aorta is increased in populations at high risk of cardiovascular disease, such as elderly people [8], and patients with hypertension [9], type 2 diabetes mellitus (T2DM) [10], and chronic kidney disease[11].

Clinical importance of arterial stiffness has been well documented; however, few studies have investigated the changes in arteries stiffness in geriatrics with angiographic carotid atherosclerosis. This study was designed to investigate whether cfPWV was associated with carotid atherosclerosis in elderly people.

\section{Subjects and Methods}

Patient Population

In this retrospective, observational study, consecutive elderly patients aged $\geq 65$ years, were selected from those who had undergone cerebral angiography at Qilu Hospital, between January

\begin{tabular}{|c|c|}
\hline KARGER & $\begin{array}{l}\text { (c) } 2011 \text { S. Karger AG, Basel } \\
1015-9770 / 11 / 0327-0016 \$ 38.00 / 0\end{array}$ \\
\hline $\begin{array}{l}\text { Fax +4161306 } 1234 \\
\text { E-Mail karger@karger.ch } \\
\text { www.karger.com }\end{array}$ & $\begin{array}{l}\text { Accessible online at: } \\
\text { www.karger.com/ced }\end{array}$ \\
\hline
\end{tabular}

W. Wu

Department of Cerebral Vascular Disease of Qilu Hospital

107 Wenhua Road

Shandong University, Jinan 250012 (China)

Tel. +86 3518216 9320, Fax +86 258480 1861, E-Mail: drwuwei@126.com 
2009 and January 2011. The selected patients were divided into two groups according to the results of cerebral angiography: those with normal carotid angiogram and those diagnosed as having carotid atherosclerosis. Carotid atherosclerosis was defined as luminal stenosis $>0 \%$ (according to North American Symptomatic Carotid Endarterectomy Trial criteria [12]), and normal coronary angiogram was defined as $0 \%$ stenosis and intima media thickness $(\mathrm{IMT}) \leq 1.0 \mathrm{~mm}$. Patients with artheriosclerosis obliterans, valvular heart disease, arrhythmia, or heart failure were excluded because of potential inaccuracy in pulse wave recording and analysis. All patients in the study provided verbal informed consent. The study protocol was approved by the Ethics Board of Qilu Hospital, Shandong University.

\section{Medical History and Examinations}

All patients were administered a standardized questionnaire for the acquisition of information about their occupation, medical history, drug use, smoking history and family medical history. Blood pressure was measured in duplicate in the supine position using the non-dominant arm in all subjects. Levels of total cholesterol (TC), triglyceride (TG) and fasting plasma glucose (FPG) were measured from fasting venous blood samples by local automated facilities. None of the patients had smoked, or drunk alcohol or coffee within $1 \mathrm{~h}$ of these examinations.

\section{PWV Measurements}

All measurements were performed in a quiet room with controlled ambient temperature. The cfPWV was performed in the supine position after $5 \mathrm{~min}$ of bed rest using an automatic waveform analyzer (Complior System, Artech-Medical corp. French), the pulse wave of the carotid and femoral arteries was analyzed, estimating the delay with respect to the ECG wave and calculating the PWV. Carotid-femoral path length was measured as the difference between the surface distances joining the suprasternal notch, the umbilicus and the femoral pulse. Carotid-femoral transit time was estimated in 8-10 sequential electrocardiogramgated femoral and carotid waveforms as the average time difference between the onset of the femoral and carotid waveforms. The foot of the pulse wave was identified using the intersecting tangent method. PWV was calculated as the carotid-femoral path length divided by the carotid-femoral transit time and expressed as $\mathrm{m} / \mathrm{sec}[13,14]$.

\section{Carotid IMT Measurements}

Measures of maximal carotid IMT were obtained in the supine position by a single ultra-sonographer. Longitudinal B-mode ultrasound images were obtained among subjects with the head turned $45^{\circ}$ from the area scanned. Gain settings were optimized to acquire far wall arterial images and limit echogenicity of the lumen. A linear array probe (Phillips Sonos 5500, Netherlands) was used for all image acquisition. The sonographer obtained 3 longitudinal views of both internal carotid arteries for a total of 6 IMT images per subject as previously described [15]. The internal carotid artery was defined to include the bulb and the initial 10 $\mathrm{mm}$ of vessel distal to separation of external from internal arteries. High resolution images were stored digitally, and read off-line by trained interpreters blinded to clinical characteristics of study participants. Near and fall wall thickness were calculated as the maximum distance between the lines.

7th International Stroke Summit

\section{Assessment of Cerebral Atherosclerosis}

Cerebral angiography was performed according to standard clinical practice, with femoral approaches using catheters $5 \mathrm{~F}$. The degree of carotid stenosis was calculated according to criteria of the North American Symptomatic Carotid Endarterectomy Trial (NASCET) [12]. A computer based edge-detection cerebral angiography analysis system was used to perform carotid analyses. Angiographic scoring was performed by observers who were involvement in the study was scoring the angiograms.

\section{Statistical Analyses}

All data analyses were performed using SPSS $^{\circledR}$ version 11.5 (SPSS Inc., Chicago, IL, USA) for Windows ${ }^{\oplus}$. Quantitative data were expressed as mean $\pm \mathrm{SD}$. Categorical data were presented as numbers and percentages. An independent-sample $t$-test was used to compare continuous data and the $\mathrm{x}^{2}$-test was used to compare categorical variables between the two groups. Bivariate analyses were performed to study associations between PWV and each of IMT and severity of carotid stenosis. A $P$-value $<0.05$ was considered to be statistically significant.

\section{Results}

The study population comprised 103 consecutive elderly patients, aged $\geq 65$ years, selected from 1025 patients who underwent cerebral angiography in Qilu Hospital, Shandong University between January 2009 and January 2011. Of these 103 patients, 55 had carotid atherosclerosis and 48 had a normal carotid angiogram. Their clinical data are shown in table 1 . There were no significant differences between the two groups for any of demographic or clinical characteristics measured.

Independent-sample $t$-test analysis demonstrated a significant difference in cfPWV and IMT between the carotid atherosclerosis group and the normal carotid angiogram group $(P=0.0261$ and 0.0180$)$ (table 2$)$.

Bivariate analysis between cfPWV and IMT in the 54 patients of the Carotid atherosclerosis group showed a positive correlation $(r=0.3222, P=0.0315$; fig. 1$)$. There was no significant correlation between PWV and carotid stenosis degree ( $r=0.1573, P=0.3137$; fig. 2$)$.

\section{Discussion}

Numerous instruments can be used to assess arterial stiffness in a non-invasive manner. cfPWV is widely considered the most established index of arterial stiffness [16]. PWV can be measured in other arterial regions, such as heart-carotid, carotid-brachial and femoral-ankle segments. Brachial-ankle PWV (baPWV) is more easily obtained and has been shown to be highly correlated

Cerebrovasc Dis 2011;32(suppl 1):16-20 
Table 1. Clinical characteristics of the subjects

\begin{tabular}{lll}
\hline & $\begin{array}{l}\text { Normal cerebral angiogram group } \\
(\mathrm{n}=48)\end{array}$ & $\begin{array}{l}\text { Carotid atherosclerosis group } \\
(\mathrm{n}=55)\end{array}$ \\
\hline Gender (male/female) & $28 / 20$ & $37 / 18$ \\
Age (years) & $68.46 \pm 3.04$ & $69.58 \pm 4.36$ \\
BMI (kg/m $\left.{ }^{2}\right)$ & $25.60 \pm 3.48$ & $24.42 \pm 2.68$ \\
SBP $(\mathrm{mm} \mathrm{Hg})$ & $125.34 \pm 10.17$ & $124.56 \pm 10.27$ \\
DBP (mm Hg) & $73.00 \pm 9.01$ & $70.38 \pm 8.74$ \\
PP (mm Hg) & $52.24 \pm 8.82$ & $51.09 \pm 9.65$ \\
MAP (mm Hg) & $89.05 \pm 7.81$ & $90.01 \pm 6.70$ \\
HR (beats/min) & $72.90 \pm 9.79$ & $71.07 \pm 10.11$ \\
FBG (mmol/l) & $5.45 \pm 0.78$ & $5.46 \pm 0.79$ \\
TC (mmol/l) & $4.39 \pm 0.68$ & $4.29 \pm 0.77$ \\
TG (mmol/l) & $1.79 \pm 0.73$ & $1.87 \pm 0.49$ \\
History of hypertension (yes/no) & $17 / 31$ & $27 / 28$ \\
History of DM (yes/no) & $5 / 43$ & $13 / 42$ \\
History of smoking (yes/no) & $21 / 27$ & $23 / 32$ \\
Family history of CI (yes/no) & $7 / 41$ & $9 / 46$ \\
ACEIs or ARBs (yes/no) & $9 / 39$ & $15 / 40$ \\
$\beta-$ blockers (yes/no) & $10 / 38$ & $16 / 39$ \\
CCBs (yes/no) & $14 / 34$ & $16 / 39$ \\
Statins (yes/no) & $15 / 33$ & $17 / 38$ \\
aspirin (yes/no) & $39 / 9$ & $42 / 13$
\end{tabular}

Data show mean \pm SD or numbers of patients.

ACEIs = Angiotensin-converting enzyme inhibitors; $\mathrm{ARBs}=$ angiotensin receptor blockers; $\mathrm{BMI}=$ body mass index; $\mathrm{CCBs}=\mathrm{cal}$ cium channel blockers; $\mathrm{CI}=$ cerebral infarction; $\mathrm{DBP}=$ diastolic blood pressure; $\mathrm{DM}=$ diabetes mellitus; $\mathrm{FPG}=$ fasting plasma glucose; $\mathrm{HR}=$ heart rate; $\mathrm{MAP}=$ mean arterial pressure; $\mathrm{NS}=$ not statistically significant $(P>0.05) ; \mathrm{PP}=$ pulse pressure; $\mathrm{SBP}=$ systolic blood pressure; TC = total cholesterol; TG = triglyceride.

Table 2. Comparison of cfPWV and IMT between the carotid atherosclerosis group and the normal cerebral angiogram group

\begin{tabular}{llrr}
\hline & $\begin{array}{l}\text { Normal cerebral angiogram group } \\
(\mathrm{n}=48)\end{array}$ & $\begin{array}{l}\text { Carotid atherosclerosis group } \\
(\mathrm{n}=55)\end{array}$ & Statistical significance \\
\hline $\operatorname{cfPWV~}(\mathrm{m} / \mathrm{s})$ & $9.84 \pm 3.86$ & $10.68 \pm 3.29$ & $P=0.0261$ \\
IMT $(\mathrm{mm})$ & $0.91 \pm 0.29$ & $1.18 \pm 0.35$ & $P=0.0180$ \\
\hline
\end{tabular}

Data are mean \pm SD.

cfPWV = Carotid-femoral pulse wave velocity; IMT $=$ intima media thickness; NS $=$ not statistically significant $(P>0.05)$.

$(r=0.76, p<0.0001)$ with carotid-femoral PWV values [17], Since the measurement of baPWV includes both central and peripheral arterier [18], confirmatory studies with cfPWV are warranted. So we select cfPWV to evaluating the arterial stiffness in elderly patients.

The present study provides the evaluation of the relationship between cfPWV and carotid atherosclerosis in elderly patients. Using the independent-sample $t$-test or $\mathrm{x}^{2}$ test no significant differences were found between the two groups in basic clinical characteristics, but patients with carotid atherosclerosis had a statistically significantly faster cfPWV than those in the normal carotid angiogram group. Krantz et al. [19] have demonstrated, in a cross-sectional study of a mixed-ethnicity population, that PWV was associated with preclinical carotid atherosclerosis independent of Framingham risk factors. It can be concluded that PWV increased in the early stages of carotid artery atherosclerosis in elderly patients when there were no significant stenosis in the carotid artery and may, therefore, have a prognostic value in diagnosing carotid atherosclerosis in elderly subjects.

In our study, a positive correlation was found between cfPWV and IMT, using bivariate analysis, but no correlation was found between cfPWV and stenosis degree of 


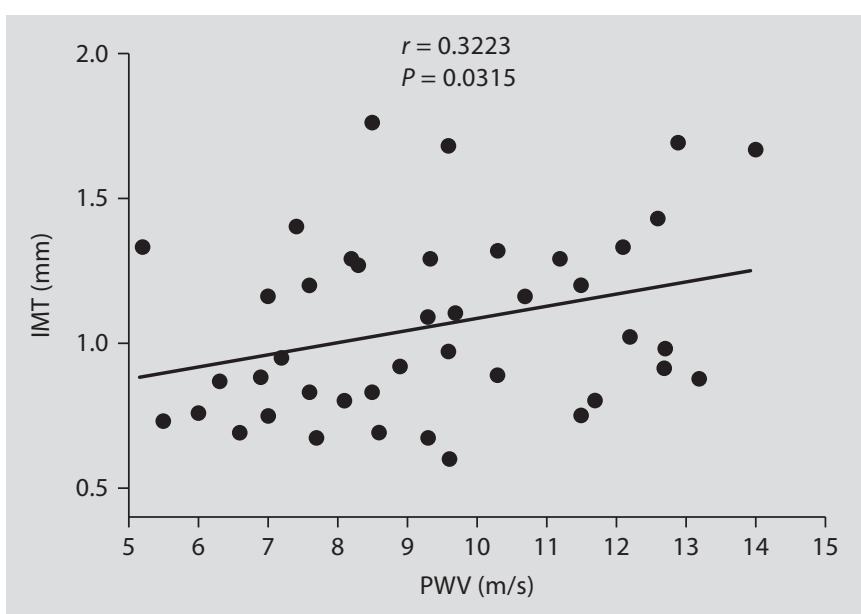

Fig. 1. Bivariate analysis between PWV and IMT in the 55 patients of the carotid atherosclerosis group showed a significant positive correlation $(r=0.3222, P=0.0315)$.

carotid artery. Overall, most studies to date has proved that IMT is an independent parameter of carotid arthrosclerosis, but it is well known that atherosclerosis with low-grade stenosis in the carotid bifurcation may result in cerebrovascular events [20]. Severity of carotid stenosis may be affected by other factors, such as inflammation, hemodynamics, and plaque volume and composition [21]. A recently case-series study provides the systematic evaluation of the relationship between CCA-IMT and arterial stiffness in subjects with type 2 diabetes and in non-diabetics, and found there is a positive correlation between CCA-IMT and the parameters used to assess arterial stiffness, including PWV [22].

Structural alterations of the arterial wall are well known to precede atherosclerosis and cardiovascular events, prior studies have shown that increased cfPWV is associated with excess risk in various high-risk and community-based samples [23, 24]. The present study confirmed that a positive correlation between cfPWV and IMT in elderly subjects and that increased cfPWV could be an early marker in indicating the vascular abnormality that leads to carotid atherosclerosis. The measurement of arterial stiffness is noninvasive, relatively low cost, easy to use and acceptable to patients. The 2007 European guidelines for the management of hypertension and guidelines for CVD prevention in clinical practice added aortic PWV as a recommended test for assessment of target organ damage [25]. Although the prognostic value of this technology has been previously investigated, but the correlation between PWV and carotid atherosclerosis has

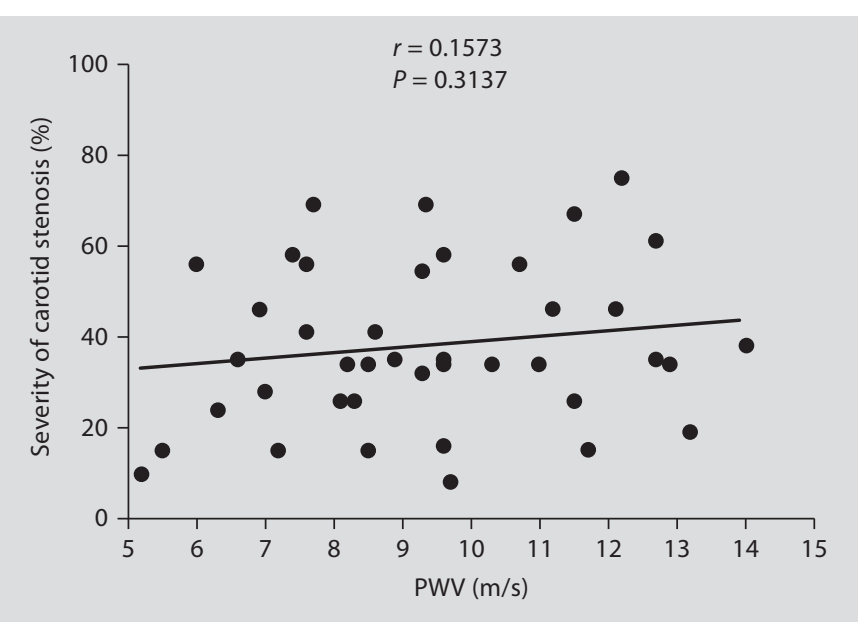

Fig. 2. Bivariate analysis between PWV and severity of carotid stenosis in the 55 patients of the carotid atherosclerosis group showed no significant correlation $(r=0.1573, P=0.3137)$.

not fully investigated. Thus, where possible, this technology should now be incorporated into longitudinal studies so that the prognostic value of PWV in carotid atherosclerosis can be fully defined.

Various limitations apply to the present study. Firstly, cerebral angiography was used to package normal and carotid atherosclerosis, which might be limited and would have caused a bias in the results. Secondly, some drugs, aside from those used in the present study, may influence arterial properties and should be investigated. Finally, the small sample size of the present study may have limited the power of this study.

\section{Acknowledgements}

This study is a joint effort of many investigators and staff members whose contribution is gratefully acknowledged. We also thank the Department of Cerebral Vascular Disease, the Department of Geriatrics of Qilu Hospital, Shandong University, and School of Physics, Shandong University, and most importantly, the patients who participated in this study.

\section{Disclosure Statement}

The authors had no conflicts of interest to declare in relation to this article. 


\section{References}

1 Ballantyne C, Arroll B, Shepherd J: Lipids and CVD management: towards a global consensus. Eur Heart J 2005;26:2224-2231.

-2 Thom T, Haase N, Rosamond W, Howard VJ, Rumsfeld J, Manolio T, et al: Heart disease and stroke statistics-2006 update: a report from the American Heart Association Statistics Committee and Stroke Statistics Subcommittee. Circulation 2006;113:e85e95.

\$3 LaRosa JC: Chemoprevention of coronary atherosclerosis: the role of lipid interventions. A position paper of the American Council on Science and Health. MedGenMed 2002; 4:12.

4 Oliver JJ, Webb DJ: Noninvasive assessment of arterial stiffness and risk of atherosclerotic events. Arterioscler Thromb Vasc Biol 2003; 23:554-566.

5 Blacher J, Asmar R, Djane S, London GM, Safar ME: Aortic pulse wave velocity as a marker of cardiovascular risk in hypertensive patients. Hypertension 1999;33:1111-1117.

-6 London GM, Blacher J, Pannier B, Guerin AP, Marchais SJ, Safar ME: Arterial wave reflections and survival in end-stage renal failure. Hypertension 2001;38:434-438.

$\checkmark 7$ Meaume S, Benetos A, Henry OF, Rudnichi A, Safar ME: Aortic pulse wave velocity predicts cardiovascular mortality in subjects $>70$ years of age. Arterioscler Thromb Vasc Biol 2001;21:2046-2050.

$>8$ Smulyan H, Asmar RG, Rudnichi A, London $\mathrm{GM}$, et al: Comparative effects of aging in men and women on the properties of the aterial tree. Am Coll Cardiol 2001;37:13741380.

9 London GM: Large artery function and alterations in hypertension. J Hypertens Suppl 1995;13:S35-S38.

-10 Taniwaki H, Kawagishi T, Emoto M, Shoji T, Kanda H, Maekawa K, et al: Correlation between the intima-media thickness of the carotid artey and aortic pulse-wave velocity in patients with type 2 diabetes. Vessel wall properties in type 2 diabetes. Diabetes Care 1999;22:1851-1857.
11 Shoji T, Nishizawa Y, Kawagishi T, Kawasaki $\mathrm{K}$, Taniwaki $\mathrm{H}$, Tabata $\mathrm{T}$, et al: Intermediatedensity lipo-protein as an independent risk factor for aotic atherosclerosis in hemodialysis patients. J Am Soc Nephrol 1998;9:12771284.

12 Henderson RD, Eliasziw M, Fox AJ, Rothwell PM, Barnett HJ: Angiographically defined collateral circulation and risk of stroke in patients with severe carotid artery stenosis. North American Symptomatic Carotid Endarterectomy Trial (NASCET) Group. Stroke 2000;31:128-132.

13 O'Rourke MF, Pauca A, Jiang X-J: Pulse wave analysis. Br J Clin Pharmacol 2001;51:507522.

14 Gomez-Marcos MA, Recio-Rodriguez JI, Rodriguez-Sanchez E, Castaño-Sánchez Y, de Cabo-Laso A, Sánchez-Salgado B, et al: Central blood pressure and pulse wave velocity: relationship to target organ damage and cardiovascular morbidity-mortality in diabetic patients or metabolic syndrome. An observational prospective study. LOD-DIABETES study protocol. BMC Public Health 2010;10: 143.

15 O'Leary DH, Polak JF, Wolfson SK Jr, Bond MG, Bommer W, Sheth S, et al: Use of sonography to evaluate carotid atherosclerosis in the elderly. The Cardiovascular Health Study. CHS Collaborative research Group. Stroke 1991;22:1155-1163.

16 Safar ME, London GM: Therapeutic studies and arterial stiffness in hypertension: recommendations of the European Society of Hypertension. The Clinical Committee of Arterial Structure and Function. Working Group on Vascular Structure and Function of the European Society of Hypertension. J Hypertens 2000;18:1527-1535.

17 Tsuchikura S, Shoji T, Kimoto E, Kayo S, Sawako H, Hidenori K, et al: Brachial-ankle pulse wave velocity as an index of central arterial stiffness. J of Atherosclerosis and Thrombosis 2010;17:658-665.

-18 Munakata M, Ito N, Nunokawa T, Yoshinaga $\mathrm{K}$ : Utility of automated brachial ankle pulse wave velocity measurements in hypertensive patients. Am J Hypertens 2003;16:653-657.
19 Krantz MJ, Long CS, Hosokawa P, Karimkahanil E, Dickinson M, Estacio RO, et al: Pulse wave velocity and carotid atherosclerosis in White and Latino patients with hypertension. BMC Cardiovascular Disorders 2011;11:15

20 Wasserman BA, Wityk RJ, Trout HH 3rd, Virmani R: Low-grade carotid stenosis: looking beyond the lumen with MRI. Stroke 2005;36:2504-2513.

21 Rozie S, Weert TT, Monye C, Homburg PJ, Tanghe HLJ, Dippel DWJ, et al: Atherosclerotic plaque volume and composition in symptomatic carotid arteries assessed with multidetector CT angiography; relationship with severity of stenosis and cardiovascular risk factors. Eur Radiol 2009;19:2294-2301.

22 Manuel Ángel Gómez-Marcos, José Ignacio Recio-Rodríguez, María Carmen PatinoAlonso, Agudo-Conde C, Gómez-Sánchez L, Rodríguez-Sánchez E, et al: Relationship between intima-media thickness of the common carotid artery and arterial stiffness in subjects with and without type 2 diabetes: a case-series report. Cardiovascular Diabetology 2011;10:3.

23 Boutouyrie P, Tropeano AI, Asmar R, Gautier I, Benetos A, Lacolley $\mathrm{P}$, et al: Laurent S. Aortic stiffness is an independent predictor of primary coronary events in hypertensive patients: a longitudinal study. Hypertension 2002;39:10-15.

24 Mattace-Raso FU, van der Cammen TJ, Hofman A, van Popele NM, Bos ML, Schalekamp MA, et al: Arterial stiffness and risk of coronary heart disease and stroke: the Rotterdam Study. Circulation 2006;113:657663.

25 Mancia G, De Backer G, Dominiczak A, Cifkova R, Fagard R, Germano G, et al: 2007 ESH-ESC Practice Guidelines for the Management of Arterial Hypertension: ESHESC Task Force on the Management of Arterial Hypertension. J Hypertens 2007;25: 1751-1762. 